\title{
Community Based Early Intervention for the Prevention of Type 2 Diabetes: A Case Report of the Kahnawake Schools Diabetes Prevention Project
}

\section{Alex Nield" ${ }^{1 \#}$ Sean Quarrell ${ }^{1 \#}$ and Stephen Myers ${ }^{1,2 \# *}$}

${ }^{1}$ School of Health Sciences and the Collaborative Research Network, University of Ballarat, Australia ${ }^{2}$ Collaborative Research Network Fellow, University of Ballarat, Australia

"Authors contributed equally

\begin{abstract}
Type 2 diabetes (T2D) is a chronic metabolic disorder that is predominately associated with lifestyle changes including reduced physical activity, poor nutrition and obesity. Despite major medical advances in the treatment of T2D, its prevalence is still increasing at an alarming rate. Accordingly, better management and prevention strategies are urgently needed to prevent the development and progression of this disease. In the last decade there have been considerable efforts to improve public health through alternative research paradigms. Community-Based Participatory Research (CBPR) is one such process by which researchers form an equal and transparent partnership with the community with the final goal of creating empowerment and societal change to facilitate action and provide solutions to promote health and well-being. One CBPR program, the Kahnawake Schools Diabetes Prevention Project (KSDPP), was initiated to promote increased physical activity and healthier eating habits among school children based on the Mohawk's "Living in Balance" philosophy. Utilizing CBPR principles, KSDPP engaged researchers and the community in all stages of the research processes. This project was community driven from the beginning and was independent of any external institutional change agent to facilitate community action and the implementation of strategies to find solutions. Although the project has been instrumental in community empowerment and societal change, several challenges remain. Accordingly, understanding the unique social, environmental and historical context that shapes lifestyle and risk factors for T2D in Native populations will help to understand the unique nature of this disease in these groups.
\end{abstract}

\section{Introduction}

Type 2 diabetes (T2D) is a progressive and chronic metabolic disorder that continues to pose a major health issue worldwide [1]. The increasing prevalence of $\mathrm{T} 2 \mathrm{D}$ is occurring in both developed and developing countries, mainly due to discernible changes in the human environment, concomitant with changes in human behaviour and lifestyle [2]. It is projected that T2D will rise significantly from an estimated 171 million people in 2000 to 366 million people in 2030 [3]. Undoubtedly, management strategies and procedures to prevent the development and progression of this disease are urgently needed.

The diabetes epidemic is most prevalent in non-Europid populations as evidenced by studies from Pacific and Indian Ocean island populations [4], Australian Aboriginal communities [5] and Native American and Canadian communities [6]. The increased prevalence of T2D in Indigenous populations has been attributed partly to genetic susceptibility [2] but the majority of cases are the result of rapid lifestyle changes (physical and social) that affect the community [7]. These changes coincide predominately with a shift from traditional lifestyle practices towards a more sedentary existence and a westerninfluenced diet [8].

Despite improved medical treatments for T2D, the public health burden of this disease continues to escalate and highlights the crucial importance for critical management and prevention strategies [9]. In this context, in the last decade there have been notable efforts for alternative research paradigms which integrate education and social mobilization of communities to improve health and reduce health inequalities [10]. This is because no single public health organization can bring together the knowledge, trust-networks, resources or capacity to address determinants that create increasing complex public health issues [11]. Accordingly, more public health organizations are building research alliances with local communities to address health issues through program prevention initiatives and management strategies $[11,12]$. These public health programs are based on the citizen and community participation in the form of community-based participatory research (CBPR).

Community-based participatory research (CBPR) engages communities and researchers in a shared partnership where each actor plays an equitable role in every phase of the research [13] with the ultimate goal of societal transformation [10]. Therefore, CBPR is not a research method, but is a process aimed at providing the community with authority in the design, implementation and analysis of the research, and dissemination of the research outcomes [14]. CBPR adopts a set of defining (but not inclusive) principles based on the following premises: (i) genuine partnership means a reciprocal learning between the community and the researchers, (ii) research efforts include a commitment to build research capacity among the community, (iii) research findings should benefit all partners, and

*Corresponding author: Stephen Myers, School of Health Sciences and the Collaborative Research Network, University of Ballarat, Mount Helen Campus, PO Box 663, Ballarat, Victoria 3353, Australia, Tel: +61 (3) 5327 9939; Fax: +61 (3) 5327 9602; E-mail: smyers@ballarat.edu.au

Received June 17, 2013; Accepted August 06, 2013; Published August 11, 2013

Citation: Nield A, Quarrell S, Myers S (2013) Community Based Early Intervention for the Prevention of Type 2 Diabetes: A Case Report of the Kahnawake Schools Diabetes Prevention Project. J Diabetes Metab 4: 277. doi:10.4172/21556156.1000277

Copyright: (c) 2013 Nield A, et al. This is an open-access article distributed under the terms of the Creative Commons Attribution License, which permits unrestricted use, distribution, and reproduction in any medium, provided the original author and source are credited. 
Citation: Nield A, Quarrell S, Myers S (2013) Community Based Early Intervention for the Prevention of Type 2 Diabetes: A Case Report of the Kahnawake Schools Diabetes Prevention Project. J Diabetes Metab 4: 277. doi:10.4172/2155-6156.1000277

(iv) CBPR involves long-term commitments and flexibility from all partners to effectively reduce inequalities [10].

This Case Report examines a CBPR program: Kahnawake Schools Diabetes Prevention Project (KSDPP), and its ongoing commitment to prevent type 2 diabetes in a Kanien'kehaka (Mohawk) community in Kahnawake, Canada. The initial program, which began in 1994, aimed to empower community members to care for their personal and family health through the continual improvement of the KSDPP based on shared visions and traditional Mohawk values.

\section{Research Focus}

Community-based participatory research for the prevention of T2D mellitus.

\section{Setting}

Kahnawake is a Mohawk community of approximately 7200 people located approximately 15 kilometres south of Montreal, Quebec, Canada. The Mohawk Nation is part of the Iroquois Confederacy whose traditional lands cover an area that includes southern Quebec and Ontario, and northern New York State (http://www.ksdpp.org/). The community was founded in 1680 and their traditional diet consisted of predominately corn, beans and squash, supplemented with foods from fishing, hunting and gathering [15]. Although the Mohawk are influenced by surrounding North America, there has been a strong commitment to reintroduce Mohawk culture and language and to preserve traditional values within the context of modern society.

\section{Problem/Issue}

Many North American Indian communities have a high incidence of T2D [6]. It has been reported that $57 \%$ of Native Americans (5-19 years of age) are overweight or obese, $30 \%$ are pre-hypertensive or hypertensive and $62 \%$ reported having a relative with diabetes [16]. The Mohawks of Kahnawake have previously been described as having both a high incidence of T2D and high rates of complications associated with this disease [17]. Eighty-six percent of diabetic patients in Kahnawake are obese. Twelve percent of adults 45-64 year olds have documented $\mathrm{T} 2 \mathrm{D}$, twice the rate of the general population of the same age. In fact, patients with T2D have the highest rate of macrovascular disease ever recorded in a North American Indian community [18]. In 1985, 48\% of T2D patients had ischemic heart disease and all diabetics with the disease for 15 years developed micro- or macrovascular complications [19].

In response to a growing concern about the high incidence of T2D and the perceived increases of obesity in children, coupled with the Mohawk tradition of caring for the future generations, prompted the Kahnawake community to partner with academic researchers to implement and evaluate a diabetes prevention program [12]. Thus, in 1994 the Kahnawake Schools Diabetes Prevention Project (KSDPP) was established with an effort to create healthy eating habits and promote physical activity within the community $[15,20]$. KSDPP is a collective partnership between the Mohawk community, academic researchers and community organizations. KSDPP was instrumental in introducing a classroom health education reform and a nutrition policy that prohibited unhealthy food and the promotion of healthier food alternatives [21]. Moreover, KSDPP's has an ongoing commitment to the monitoring and evaluation of the program, and in providing education tools and resources in an effort to prevent diabetes in the community over the long-term.

\section{Intervention and evaluation}

The main focus of KSDPP was the development and implementation of an educational school health program curriculum for 458 students (260 students from an English school and 198 from a Mohawk immersion school; ages between 6 and 11) in grades 1-6 [15,21]. Anthropometric parameters including weight measurements, BMI and skinfold thickness were performed by one nurse during school hours while questionnaires were collected on socio-demographic and lifestyle variables such as physical activity, sedentary behaviour and nutritional status [22].

The school curriculum included information on diabetes, healthy eating options, and physical activity and fitness testing. The diabetes component of the curriculum provided information on the health impacts of diabetes and prevention strategies. The lessons from healthy eating options helped students understand food preparation, body image, healthier snack food options and factors that influence eating habits and behaviour, while the fitness lessons described the benefits of daily physical activity on health outcomes [15].

Within the community activities included the regular use of media such as local newspapers and radio announcements; the frequent use of posters in public places, and press coverage of events to report results back to the community [15,22]. Environmental and policy changes supported by KSDPP included a ban on "junk" food sold on the school premises, and the construction of walking and cycling paths.

\section{Strengths/benefits of KSDPP}

KSDPP is a partnership between the Mohawk community of Kahnawake, organizations, community researchers and academic researchers (Figure 1). These stakeholders are involved in KSDPP through their association with, (i) KSDPP staff, (ii) a KSDPP Community Advisory Board (CAB), (iii) a supervisory board, and (iv) research teams and community affiliations [23] (Table 1). KSDPP

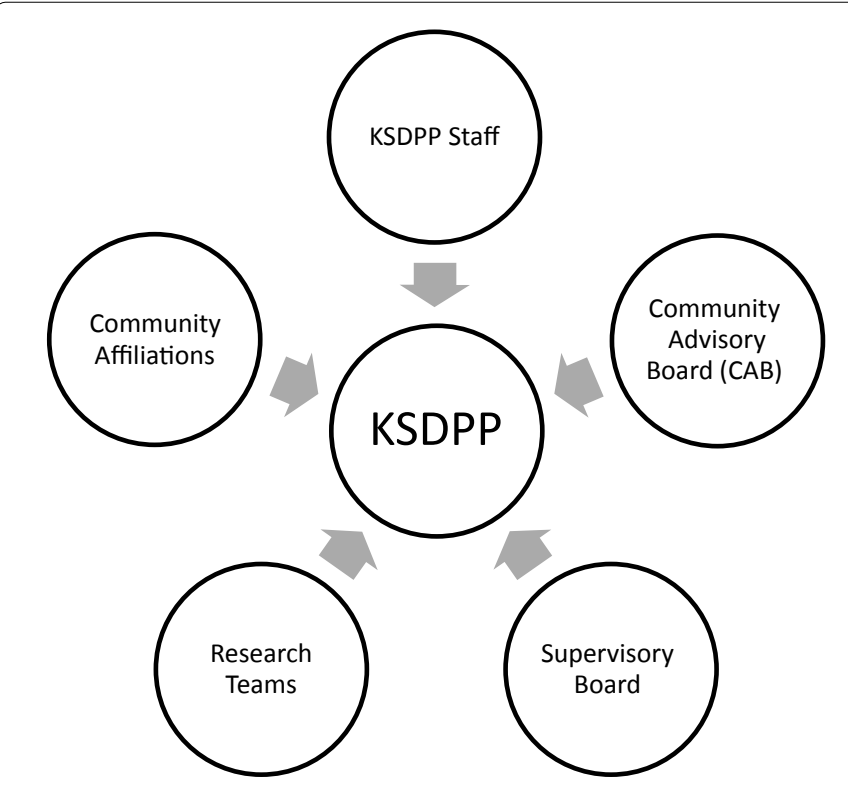

Figure 1: Kahnawake Schools Diabetes Prevention Project (KSDPP) organization.

KSDPP consists of research teams, community affiliates, KSDPP staff, a community advisory board (CAB) and a supervisory board. 
Citation: Nield A, Quarrell S, Myers S (2013) Community Based Early Intervention for the Prevention of Type 2 Diabetes: A Case Report of the Kahnawake Schools Diabetes Prevention Project. J Diabetes Metab 4: 277. doi:10.4172/2155-6156.1000277

Page 3 of 6

\begin{tabular}{|l|l|}
\hline Partner & Role \\
\hline KSDPP staff & Diabetes prevention facilitators and trainers, administration staff and community researchers. \\
\hline $\begin{array}{l}\text { Community Advisory } \\
\text { Board (CAB) }\end{array}$ & $\begin{array}{l}\text { Community members from diverse sectors of the community including those from the public health and social sciences, political and spiritual } \\
\text { representatives, and community members with a general interest in the project. }\end{array}$ \\
\hline Supervisory board & Community, political and academic representatives ensuring financial accountability and transparency. \\
\hline $\begin{array}{l}\text { Research team and } \\
\text { community affiliations }\end{array}$ & $\begin{array}{l}\text { Academic researchers defined by their association with universities; community researchers including health and education professionals } \\
\text { with research responsibilities, and community affiliates that include organizations and other community members that support the KSDPP } \\
\text { intervention and research but are not involved in KSDPP committees }\end{array}$ \\
\hline
\end{tabular}

Adapted from Cargo et al. 2011 [23]

Table 1: Role of each partner in the Kahnawake Schools Diabetes Prevention Project.

is governed through stakeholder participation in many aspects of the project including: (i) maintaining KSDPP's activities through a collective vision, (ii) upholding the daily KSDPP operations, (iii) a KSDPP CAB, (iv) the planning, intervention, implementation and dissemination of research outputs, and (v) ethical considerations [23]. The decisions of the KSDPP were supported by a collective decisionmaking process that involved representatives from partner groups. Specifically, KSDPP staff attended research meetings, and academics and KSDPP staff were present at CAB meetings [23]. It is noteworthy to mention that the $\mathrm{CAB}$ was created to ensure broad representation of community involvement, community empowerment and to facilitate and encourage the long-term sustainability of the program [15]. This ongoing program is represented by researchers from the community and the academic institutions of McGill University, Universite de Montreal and Queen's University.

The KSDPP is focused on elementary school children, their families and the community with the aim to promote daily physical activity and good nutritional habits among Kahnawake children to help prevent future generations from suffering the same burden of disease [24]. Other important objectives are to mobilize and engage the Kahnawake community in an effort to foster empowerment and ownership through shared vision and participation in all aspects of the project and to build capacity to ensure the sustainability of KSDPP goals, objectives and activities in the future $[13,24]$.

KSDPP aims to prevent T2D in the community through CBPR and both traditional lifestyle modifications (such as promoting regular exercise and better nutrition) with a KSDPP takes a holistic approach to preventing T2D in the community through its "Living in Balance" philosophy (Figure 2) (http://www.ksdpp.org). "Living in Balance" reflects the preservation of a healthy well-being; mind, body, emotion and spirit. The messages of the KSDPP are deep-rooted in this traditional philosophy of health and well-being and several strategies to embed this philosophy within the community include (i) a health education program for students in grades 1-6, (ii) raising diabetes awareness, and (iii) community-based activities all within the overall goal of "Living in Balance".

(i) The health education program aims to provide information on diabetes and the complications associated with this disease. The curriculum was created by a dietician and community health nurses and contains lessons on nutrition, fitness, diabetes, lifestyle choices, understanding the human body and diabetes risk factors and symptoms [15].

(ii) Raising diabetes awareness: KSDPP provides community workshops that are designed to enable and empower participants to facilitate or help enhance a diabetes prevention or wellness program in their community.

(iii) Community-based activities: Kahnawake has a long tradition of community recreation and aims to build on the existing healthy lifestyle institutions visions (http://www.ksdpp.org/ elder/intervention.php). A key partner is the Kahnawake Youth Centre that hosts a Winter Carnival promoting healthy foods, and many physical activities such as annual races for health; walk, jog or bike to work, and physical activities fairs.

Today, the KSDPP continues to strive to implement objectives within the community and improve on the lessons learned from the earlier studies. These are being used to build on the existing public health framework models to identify ways that they can be utilized in other Aboriginal communities.

These include:

- The continual improvement of school curriculum activities for Kahnawake children.

- Provision of diabetes prevention activities for families and the community in collaboration with local organizations.

- Continued capacity building and sustainability efforts within Kahnawake.

- Sharing and expanding upon the experiences of Kahnawake diabetes initiatives within Kahnawake.

\section{CBPR Principles}

The KSDPP of intervention draws on several CBPR principles/ strategies that support KSDPP's objectives of promoting community capacity building and ownership of the project. These include:

The KSDPP engagement with community and university research partners in all phases of the project: Thus, community members are able to influence and direct over those conditions that affect community health [21]. Importantly, academics should not be seen as "societies knowledge elites" and therefore should enter the program as reciprocal co-learners into a "learning community" [25]. These learning alliances can often lead to novel ideas and solutions to issues through local knowledge processes and information networks. Moreover, a sense of belonging experience through positive partnerships can also promote health and well-being. For example, studies on social participation have shown that people, who hold important roles in a supportive social context are generally healthy, suffer less disability and recover more rapidly from illness [26].

Integration of community members as equal partners: Community members had major influences throughout the project in terms of the design, intervention strategy and dissemination of information within the schooling system and the community as a whole. Thus, approaches that foster community empowerment suggest that community members should direct the course of intervention and action through participatory activities that involve decision-making [27] and communication of research findings [27,28]. For example, members of the $\mathrm{CAB}$ advise on many facets of the program including 


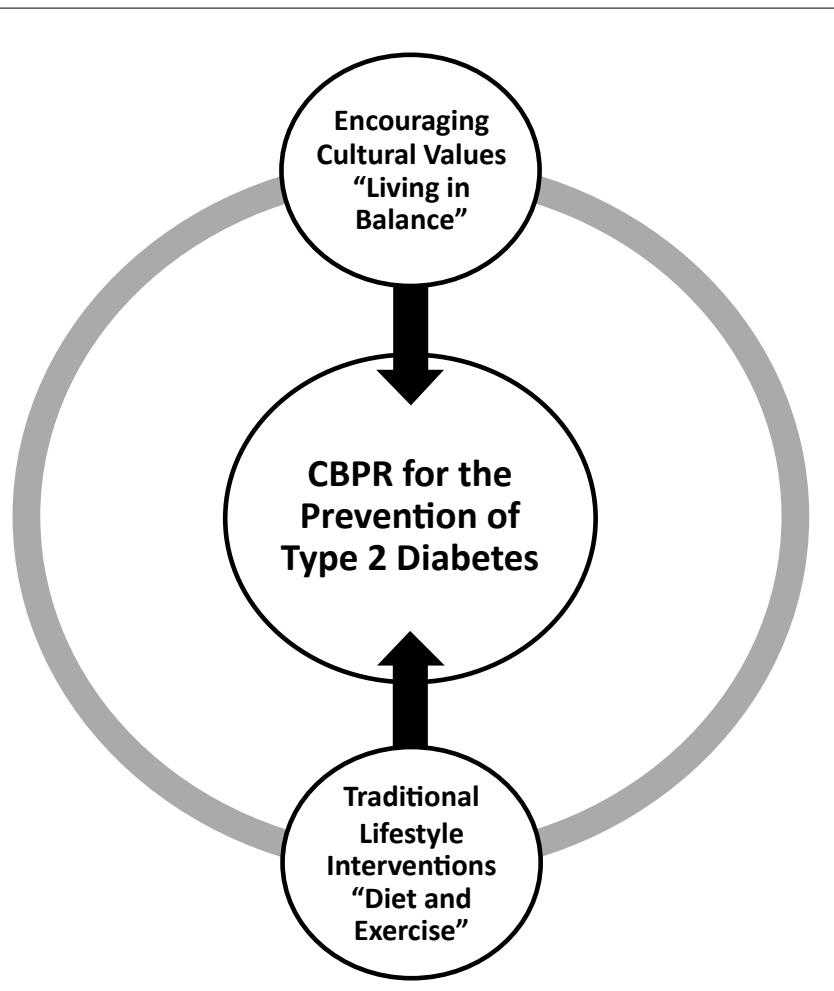

Figure 2: Traditional lifestyle interventions and "Living in Balance" philosophy within Community-based Participatory Research.

Traditional lifestyle modifications (such as diet and exercise) and the "Living in Balance" philosophy of the Mohawk peoples are interconnected through the promotion of empowerment and encouraging cultural values.

the intervention and evaluation objectives, activities, and culture and project concerns, and are also encouraged to become role models to promote healthy lifestyles in organizations and the community of Kahnawake [15].

Integration of intervention and evaluation: In the community, the research component (intervention and evaluation) of the KSDPP was identified as being part of the community project. Aboriginal communities recognised that Kahnawake was creating innovative approaches to diabetes prevention. This created a source of pride among the community and was instrumental in the preservation of participatory responses throughout the project [24].

Organisational and programmatic flexibility: Flexibility and adaptation were crucial conditions for the survival of the program. KSDPP was implemented when funding was scarce and funding agencies were reluctant to commit to long-term projects [24]. Despite a successful implementation and community awareness of the project, alternative funding sources was needed. Eventually, funding was acquired from the Mohawk Council of Kahnawake, Kahnawake Shakotiia'takehnhas Community Services, and the Kahnawake Education Centre. However, each of these funding agencies had their own conditions which challenged the integrity of the project. Accordingly, drawing on the principles of CBPR in remaining flexible and adaptive in the course of the dynamic nature of the project helped all members to stay focused and re-evaluate their original vision.

Making the project a learning opportunity for all: The development of partnerships between the KSDPP and other organisations during the early stages of the project allowed for the integration of several levels of expertise, with none having authoritative status [24]. Community members and organisations were not considered as passive agents of someone else's vision. They contributed to the dissemination of knowledge to the community and contributed to ideas on the strategies of the program.

\section{Lessons learned}

The successful implementation of KSDPP was facilitated by a number of essential strategies that brought together the community's vision of creating a healthier life for its people and building capacity among the population through empowerment, equality, and leadership. Moreover, KSDPP demonstrates how a dynamic process of health promotion can be successfully implemented through the establishment of an equal partnership between community groups and academic researchers. Furthermore, the involvement of staff and community members as equal players in the project was essential for the diffusion and dissemination of information and helped facilitate the integration of all the program components. The project has been successful in establishing an intervention program with community groups and academic researchers. The program has grown, and it has sustained itself despite critical policy changes in funding agencies [24]

Previously, an eight year study to determine the effectiveness of the KSDPP identified that there was no discernible impact on reducing obesity prevalence in the children [22]. It was suggested that adverse environmental factors such as the introduction of satellite television, increased disposable income, and the increasing availability of fastfood restaurants in the region surrounding Kahnawake, overwhelmed behavioural and education strategies that were designed to reduce energy intake and promote physical activity [29]. Similarly, studies from an extensive two year "school-based obesity intervention, Project Energize" to improve childhood obesity and cardiovascular risk factors in primary school children in the Waikato region of New Zealand showed minor improvements in health however this was dependent on ethnicity, rurality and sex [30]. For example, Maori children had a tendency for greater increases in relative body size, body fat and blood pressure. It was also suggested that children's behaviours outside of the school environment could not be accounted for [30], and therefore, external factors similar to those as in Kahnawake may contribute to superseding those behavioural and education strategies in the schoolbased program.

It is noteworthy to mention that while the effectiveness of the initial program of preventing obesity in school children was poor, the longevity of KSDPP and its ability to mobilize and empower the community to take collective action for the prevention of diabetes should be praised. Moreover, KSDPP remains diligent in requiring and providing new knowledge and information from these lessons learned that can contribute to community public health promotion and the sustainable improvement of CBPR within a culturally relevant context. Native communities' value this method of research to ensure that cultural relevance is upheld and their participation in decisions for action helps create new knowledge that builds on existing models of community health [15].

While the Mohawk community of Kahnawake has been instrumental in initiating a CBPR project that has been successfully integrated into their traditional philosophy "Living in Balance", several challenges remain. The prevention of obesity and diabetes requires not only traditional lifestyle changes but also must take into account political, socioeconomic factors, cultural and worldview perceptions 
Citation: Nield A, Quarrell S, Myers S (2013) Community Based Early Intervention for the Prevention of Type 2 Diabetes: A Case Report of the Kahnawake Schools Diabetes Prevention Project. J Diabetes Metab 4: 277. doi:10.4172/2155-6156.1000277

Page 5 of 6

that are scale and place-specific. Therefore, it will be important to understand how community participation and societal action within an economic and political independence modifies the determinants of health. Similarly, interventions that specifically target determinants of lifestyle change and factors such those associated with ethnicity, sex and socio-economic status may be useful in supporting participants through their change process. These processes would require longer intervention periods to achieve long-lasting lifestyle changes and the sustainability of these changes would most likely be successful with greater community empowerment, mobilization and participation.

In this context, not only has the KSDPP facilitated the tools to provide information and education to students on healthy lifestyle choices in an effort to reduce obesity and in extension diabetes in the community, but it has also implemented empowerment within the community to take charge and action of the health issues and augment their traditional beliefs and practices with modernity that is acquired from western influences.

\section{Summary of Positive Outcomes from KSDPP}

- Collective community vision to create a healthy community.

- Community empowerment, equality, ownership and leadership.

- A transparent and equal partnership between community groups and academia.

- Project longevity and the opportunity to learn and build on the lessons learned.

- Promotion of holistic health central to Mohawk traditions.

\section{Conclusion}

The Mohawk community of Kahnawake, Canada represents an indigenous population with a high incidence of childhood and adult obesity concomitant with T2D. The increased rate of diabetes in this population prompted community representatives to initiate a CBPR project with academic researchers, supervisory groups and the community to implement an early intervention program. KSDPP represents an excellent example of a self-sustaining program that was initiated to mobilize and engage the Kahnawake community to foster stewardship and empowerment to build capacity and shared vision to ensure the sustainability of KSDPP goals, objectives and activities in the future. This model could prove to be a template from which larger scale intervention programs could be designed and implemented throughout the world. Furthermore, programs designed around the paradigms of the KSDPP and the principles of CBPR may help educate future generations on healthy lifestyle choices, and in extension potentially increase the overall health of the target community; not only in indigenous populations like the Kanien'kehaka tribe, but also in the general population.

\section{Questions}

Can an early intervention program with a longer intervention period instil healthy lifestyle habits in its participants that are carried on into their adult lives, therefore leading to a reduction in the incidence of $\mathrm{T} 2 \mathrm{D}$ ?

Can an intervention program based on the KSDPP be designed on a much larger scale for a population with mixed community and cultural backgrounds?

\section{References}

1. Myers SA, Nield A, Myers M (2012) Zinc transporters, mechanisms of action and therapeutic utility: implications for type 2 diabetes mellitus. J Nutr Metab: 173712.

2. Zimmet P, Alberti KG, Shaw J (2001) Global and societal implications of the diabetes epidemic. Nature 414: 782-787.

3. Shin JA, Lee JH, Kim HS, Choi YH, Cho JH, et al. (2012) Prevention of diabetes: a strategic approach for individual patients. Diabetes Metab Res Rev 28: 79-84.

4. Liu LL, Yi JP, Beyer J, Mayer-Davis EJ, Dolan LM, et al. (2009) Type 1 and Type 2 diabetes in Asian and Pacific Islander U.S. youth: the SEARCH for Diabetes in Youth Study. Diabetes Care 32: S133-140.

5. Daniel M, Rowley KG, McDermott R, Mylvaganam A, O'Dea K (1999) Diabetes incidence in an Australian aboriginal population. An 8-year follow-up study. Diabetes Care 22: 1993-1998.

6. Gittelsohn J, Rowan M (2011) Preventing diabetes and obesity in American Indian communities: the potential of environmental interventions. Am J Clin Nutr 93: 1179S-83S

7. Receveur O, Morou K, Gray-Donald K, Macaulay AC (2008) Consumption of key food items is associated with excess weight among elementary-schoolaged children in a Canadian first nations community. J Am Diet Assoc 108: 362-366.

8. Naqshbandi M, Harris SB, Esler JG, Antwi-Nsiah F (2008) Global complication rates of type 2 diabetes in Indigenous peoples: A comprehensive review. Diabetes Res Clin Pract 82: 1-17.

9. Katula JA, Vitolins MZ, Morgan TM, Lawlor MS, Blackwell CS, et al. (2013) The Healthy Living Partnerships to Prevent Diabetes study: 2-year outcomes of a randomized controlled trial. Am J Prev Med 44: S324-332.

10. Wallerstein NB, Duran B (2006) Using community-based participatory research to address health disparities. Health Promot Pract 7: 312-323.

11. Mantoura P, Gendron S, Potvin L (2007) Participatory research in public health: creating innovative alliances for health. Health Place 13: 440-451.

12. Cargo M, Delormier T, Lévesque L, Horn-Miller K, McComber A, et al. (2008) Can the democratic ideal of participatory research be achieved? An inside look at an academic-indigenous community partnership. Health Educ Res 23: $904-$ 914

13. Macaulay AC, Ing A, Salsberg J, McGregor A (2007) Community-Based Participatory Research: Lessond From Sharing Results With the Community: Kahnawake Schools Diabetes Prevention Project. The John Hopkins University Press 1: 143-152.

14. Blumenthal DS (2011) Is community-based participatory research possible? Am J Prev Med 40: 386-389.

15. Macaulay AC, Paradis G, Potvin L, Cross EJ, Saad-Haddad C, et al. (1997) The Kahnawake Schools Diabetes Prevention Project: intervention, evaluation, and baseline results of a diabetes primary prevention program with a native community in Canada. Prev Med 26: 779-790.

16. Brown B, Noonan C, Harris KJ, Parker M, Gaskill S, et al. (2013) Developing and piloting the Journey to Native Youth Health program in Northern Plains Indian communities. Diabetes Educ 39: 109-118.

17. Montour LT, Macaulay AC, Adelson N (1989) Diabetes mellitus in Mohawks of Kahnawake, PQ: a clinical and epidemiologic description. CMAJ 141: 549-552.

18. Macaulay AC (1988) Diabetic education program in the mohawk community of kahnawake, quebec. Can Fam Physician 34: 1591-1593.

19. Macaulay AC, Montour LT, Adelson N (1988) Prevalence of diabetic and atherosclerotic complications among Mohawk Indians of Kahnawake, PQ. CMAJ 139: 221-224.

20. Mercille G, Receveur O, Macaulay AC (2010) Are snacking patterns associated with risk of overweight among Kahnawake schoolchildren? Public Health Nutr 13: $163-171$.

21. Cargo M, Levesque L, Macaulay AC, McComber A, Desrosiers S, et al. (2003) Community governance of the Kahnawake Schools Diabetes Prevention Project, Kahnawake Territory, Mohawk Nation, Canada. Health Promot Int 18: 177-187. 
Citation: Nield A, Quarrell S, Myers S (2013) Community Based Early Intervention for the Prevention of Type 2 Diabetes: A Case Report of the Kahnawake Schools Diabetes Prevention Project. J Diabetes Metab 4: 277. doi:10.4172/2155-6156.1000277

22. Paradis G, Lévesque L, Macaulay AC, Cargo M, McComber A, et al. (2005) Impact of a diabetes prevention program on body size, physical activity, and diet among Kanien'keha:ka (Mohawk) children 6 to 11 years old: 8-year results from the Kahnawake Schools Diabetes Prevention Project. Pediatrics 115: 333-339.

23. Cargo M.D, Delormier T, Levesque L, McComber AM, Macaulay AC (2011) Community Capacity as an "Inside Job": Evolution of Perceived Ownership Within a University-Aboriginal Community Partnership. Am J Health Promot 26: 96-100.

24. Potvin L, Cargo M, McComber AM, Delormier T, Macaulay AC (2003) Implementing participatory intervention and research in communities: lessons from the Kahnawake Schools Diabetes Prevention Project in Canada. Soc Sci Med 56: 1295-1305.

25. Wiber M, Charles A, Kearney J, Berkes F (2009) Enhancing community empowerment through participatory fisheries research. Marine Policy 33: 172 179
26. Letcher AS, Perlow KM (2009) Community-based participatory research shows how a community initiative creates networks to improve well-being. Am J Prev Med 37: S292-299.

27. Jagosh J, Macaulay AC, Pluye P, Salsberg J, Bush PL, et al. (2012) Uncovering the benefits of participatory research: implications of a realist review for health research and practice. Milbank Q 90: 311-346.

28. Cornwall A, Jewkes $R$ (1995) What is participatory research? Soc Sci Med 41 1667-1676.

29. Willows ND, Hanley AJ, Delormier T (2012) A socioecological framework to understand weight-related issues in Aboriginal children in Canada. Appl Physiol Nutr Metab 37: 1-13.

30. Rush E, Reed P, McLennan S, Coppinger T, Simmons D, et al. (2012) A schoolbased obesity control programme: Project Energize. Two-year outcomes. $\mathrm{Br} J$ Nutr 107: 581-587. 